\section{Stop slaughter of migrating songbirds}

A new strategy is needed to stop the illegal trapping and killing of millions of songbirds every year in the Mediterranean region, where gigantic vertical nets intercept major migration flyways (see also Nature 529, 452-455; 2016). In the western Mahgreb in North Africa, this carnage is collateral damage to the area's cultural fancy for pet goldfinches (Carduelis carduelis), which dates back to around 700 and the Umayyad dynasty.

The goldfinch has only recently been officially protected in Algeria, Tunisia and Morocco, where its populations have been declining rapidly over the past two decades. The price of a single live bird (pictured) is now US\$50-500, equivalent to $25-250 \%$ of the typical local monthly salary. This has caused trapping and by-catch to escalate. Many of the captured goldfinches perish under poor transport conditions.

I suggest that local people should be taught to divert their admiration for the goldfinch's charms into ensuring its protection. Netting would stop if instead the goldfinch became an emblematic conservation symbol of the region, and a 'safety umbrella' for other migrating Palaearctic songbirds (see J.-M. Roberge and P. Angelstam Conserv. Biol. 18, 76-85; 2004). Rassim Khelifa Université Mouloud Mammeri de Tizi Ouzou, Algeria. rassimkhelifa@gmail.com

\section{Don't undervalue the social sciences}

Too many physicists, chemists and biologists perceive the social sciences and humanities as less rigorous and less intellectually demanding domains than their own. Research into expert performance calls these attitudes into question.

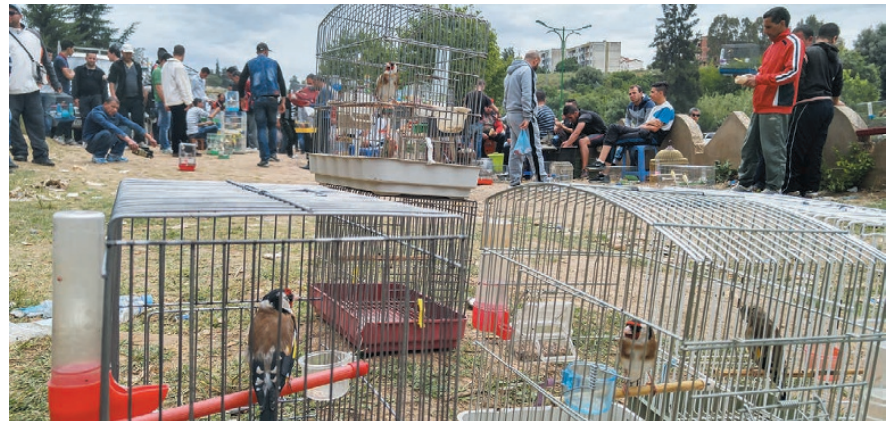

Goldfinches for sale in an Algerian market, despite being officially protected.

Thousands of hours of deliberate practice are needed to become highly competent in any endeavour that requires skill (see The Cambridge Handbook of Expertise and Expert Performance Cambridge Univ. Press; 2006). Moreover, the time invested before making a world-class contribution to any major field is similar, be it in chess, music, basketball, history or flying a plane (A. Ericsson and R. Pool Peak Bodley Head; 2016).

So, distinguished scholars from different fields are likely to be comparably proficient in the skills relevant to their work. Assuming that top researchers have devoted roughly the same amount of effort to developing their domain-specific skills, the wider implication is that different fields are roughly equally advanced in terms of dealing with the challenges they face.

If physics, say, seems more developed than social science, then this may be because the field has been established for longer or that the challenges are easier to overcome. Brian Martin University of Wollongong, Australia. bmartin@uow.edu.au

\section{US panel risks infant and researcher lives}

As the chief executives of the biotech companies Ganogen and StemExpress, we are among a broad sweep subpoenaed along with scientists, graduate students and physicians also engaged in research involving fetal tissue - by the US House Select Investigative Panel on Infant Lives. In our view, this witch-hunt endangers infants and researchers and must end.

The panel's stated aim is to "get the facts about medical practices of abortion service providers and the business practices of the procurement organizations who sell baby body parts". On 1 June, it released the names, addresses, e-mail contacts and telephone numbers of many of us in an open letter to the US Department of Health and Human Services. We consider this to be a callous disregard of the threat posed by activists to medical researchers who are in fact engaged in saving young lives (see Nature Biotechnol. 34, 445; 2016).

Research involving fetal tissue led to vaccines against polio, rubella and chickenpox. It was central to proving the link between Zika virus and infant microcephaly (H. Tang et al. Cell Stem Cell 16, 587-590; 2016), and is essential for developing a vaccine against the virus (Nature 532, 16; 2016). The chair of the panel, Representative Marsha Blackburn of Tennessee, should note that her constituents, and those of committee members Diane Black (Tennessee) and Vicki Hartzler (Missouri), are especially vulnerable to Zika because the mosquito vector, Aedes aegypti, is more prevalent in the southern states.

Eugene Gu Ganogen Research
Institute, Redwood City, USA. Cate Dyer StemExpress, Placerville, USA. eugenegu@ganogen.org

\section{Food security needs social-science input}

As members of the ClimateResilient Open Partnership for Food Security project supported by the World Wide University Network (see go.nature.com/28ygwtc), we contend that basic socialscience theory and methods could transform interventions aimed at improving food production.

Food security calls for agricultural advances, adaptation to climate change and more efficient use of natural resources. Just as important are the social and political considerations of reforming food production and distribution systems.

All too often, poor communication between the scientific community and the public, including potential users, impedes utilization of new technologies. Social networks, power inequalities and institutional resistance to change must all be taken into account if the system is to be reformed (see W. W. Powell et al. in The Science of Science Policy 31-55, Stanford Univ. Press; 2011).

We therefore suggest that research consortia in food security and their funding agencies should include social scientists from the outset (see A. Viseu Nature 525, 291; 2015). This would dramatically enhance project management and conceptual development by dealing with the complex interactions between natural and social factors.

Klaus Nüsslein ${ }^{\star}$, Om Parkash Dhankher ${ }^{\star}$ University of Massachusetts Amherst, USA. nusslein@microbio.umass.edu ${ }^{\star}$ Supported by 13 signatories (see go.nature.com/299szyy). 